\title{
MONITORAMENTO DE PARÂMETROS FÍSICOS E AMBIENTAIS DE CAMADAS DE SOLO ESTABILIZADAS COM LODO DE ETA E DE ETE
}

\author{
Lêda Christiane Lopes Lucena* \\ José de Arimateia Silva** \\ Paulo Germano Tavares Marinho Filho*** \\ Manoel Gualberto Portela*****
}

RESUMO: O descarte inadequado dos resíduos gerados em ETA's e/ou ETE's configurase como crime ambiental pelo potencial poluidor dos resíduos. Portanto, a gestão do lodo bruto é uma tarefa relevante pelos riscos epidemiológicos e a ocorrência de metais pesados. A utilização de técnicas de estabilização/solidificação é um meio de permitir o tratamento de resíduos. Este trabalho teve como objetivo monitorar o impacto ambiental causado pela utilização de resíduos do lodo em base e sub-base de pavimentos, por meio da construção de um modelo reduzido, das misturas de solo + lodo + estabilizante, para o lodo de ETE e para o lodo de ETA. Foram analisados durante um ano parâmetros como umidade, $\mathrm{pH}$, recalque e concentração de metais. Os resultados apontaram que o uso do processo de estabilização/solidificação com os resíduos de lodo para fins de pavimentação é uma solução que pode equacionar problemas ambientais e econômicos.

PALAVRAS-CHAVE: Estabilização; Lodo; Metais pesados.

\section{MONITORING PHYSICAL AND ENVIRONMENTAL PARAMETERS OF SOIL LAYERS STABILIZED WITH ETA AND ETE SLUDGE}

ABSTRACT: Inadequate disposal of wastes in ETA and ETE is an environmental crime owing to high potential waste pollutant. The management of crude sludge is a relevant task because of epidemiological risks and the presence of heavy metals. Wastes are treated by stabilization and solidification techniques. Current study monitors the environmental impact caused by sludge wastes in pavement layers and sub-layers by building a miniature model of mixtures soil+sludge+stabilizer, for ETE and ETA sludge. Parameters humidity, $\mathrm{pH}$, calque and heavy metal concentration were analyzed during the year. Results indicated that the stabilization/solidification process with sludge wastes for pavements is a solution that may solve economic and environmental issues.

KEY WORDS: Stabilization; Sludge; Heavymetals.

\footnotetext{
Doutora em Engenharia Civil pela Universidade Federal de Pernambuco (UFPE); Docente da Universidade Federal de Campina Grande (UFCG), Brasil. E-mail: ledach@uol.com.br

** Doutor em Engenharia de Processo pela Universidade Federal de Campina Grande (UFCG), Brasil.

${ }^{* * *}$ Mestrando em Engenharia Civil Universidade Federal de Campina Grande (UFCG), Brasil.

**** Mestrando em Engenharia Civil Universidade Federal o Ceará (UFC), Brasil.
} 


\section{INTRODUÇÃO}

O lançamento dos resíduos gerados em ETA's (Estação de Tratamento de Água) e/ou ETE's (Estação de Tratamento de Esgoto) em corpos d'água é considerado crime ambiental, de acordo com a lei 9.605/98, pelos efeitos diretos causados ao ambiente aquático do corpo receptor e danos à fauna aquática ( $\mathrm{ACHON}$; BARROSO; CORDEIRO, 2008). A resolução $\mathrm{n}^{0} 430$ do Conselho Nacional do Meio Ambiente (BRASIL, 2011) determina as condições que devem ser cumpridas para 0 lançamento de efluentes de qualquer fonte poluidora, direta ou indiretamente nos corpos d'água. Tais condições impedem o lançamento, sem prévio tratamento, pela grande concentração de sólidos sedimentáveis presentes nestes resíduos (GUERRA; ANGELIS, 2005). O resultado do descuido com o gerenciamento destes resíduos pode provocar problemas ambientais, sociais e sanitários à população.

O lodo, proveniente de ETE, apresenta em sua composição uma variedade de patógenos, vírus, parasitas e fungos que, apesar de serem reduzidos quando submetidos a processos de estabilização na ETE, sobrevivem e podem representar riscos à saúde humana e animal. Ou seja, o lodo de ETE pode conter metais pesados, patógenos, e compostos orgânicos, sendo considerado resíduo perigoso e cujo tratamento é oneroso (KE et al., 2012; LIN et al., 2012). A construção civil apresentase como uma alternativa para a disposição final destes resíduos seja em substituição a parte do cimento no concreto (CHANG et al., 2010; DYER; HALLIDAY; DHIR, 2011; HAMOOD; KHATIB, 2012; LIN et al., 2012), a produção de tijolos e telhas e aterros em estradas (SMOL et al., 2015), ou como agregado em misturas asfálticas (TENZAABRIL; SAVAL; CUENCA, 2015).

A quantidade de lodo produzido nas ETA aumentou substancialmente nas últimas décadas em função do crescimento da população e do aumento da capacidade de tratamento das ETA (LIU et al., 2013). O lodo de ETA apresenta quantidades elevadas de substâncias poluentes, nitrogênio, fósforo e compostos orgânicos proveniente da descarga nos cursos de água, muitas vezes clandestinas, de indústrias e proveniente de práticas agrí́colas (PASCUAL et al., 2015; GUERRERO; BEVILAQUA, 2015). Os custos com o tratamento do resíduo podem chegar até $50 \%$ do valor total gasto em uma ETA (JANG; AHN, 2015). Além de esses lodos 
conterem metais pesados, eles apresentam também elevadas concentrações de sólidos, demanda química de oxigênio (DQO) e alta turbidez, que podem causar assoreamento de cursos d'águas, criação de bancos de lodo, alterações na cor e na composição química, além de alterações biológicas (TEIXEIRA et al., 2006; PEREIRA, 2011). Atualmente tem-se estudado o emprego deste resíduo em substituição parcial do cimento (LIN; ZHU; HAN, 2013; LI et al., 2013), em concreto (AYDILEK; EDIL, 2008), como agregados (BRAR et al., 2009) e em pavimentos (D'ANDREA; FUSTAINO; TOZZO, 2014).

Estão sendo revistas as soluções antes adotadas para esses resíduos, disposição em aterro sanitário e incineração. Na Europa, a partir de 2013, foi proibido o descarte em aterros pela possibilidade de contaminação do subsolo e lençol freático, quanto à incineração, além de ser um processo caro, é necessária a desidratação de lamas antes da queima para prevenir a poluição do ar (PROUST; MATHÉ; LÉVÊQUE, 2013).

Deste modo, resíduos, como os lodos de ETE e ETA merecem atenção especial quanto aos impactos ambientais provocados por sua destinação final. A utilização de técnicas de estabilização/solidificação é um meio de permitir o tratamento de resíduos. O encapsulamento é um estágio de pré-tratamento pelo qual os constituintes perigosos de um resíduo são transformados e mantidos em suas formas menos solúveis ou tóxicas confinados em cápsulas, partículas ou blocos.

Lucena et al. (2014-a) e Lucena et al. (2014-b) realizaram estudos envolvendo misturas de solo, lodo, de ETA e ETE, e estabilizantes (cal, cimento e emulsão) em diferentes proporções, visando analisar propriedades dos materiais, e suas modificações por meio de intervenções mecânicas ou químicas.

Lucena et al. (2014-a) e Lucena et al. (2014-b), ao analisarem a estabilização dos lodos, elencaram o percentual e o estabilizante que proporcionaram maior coesão das partículas ao atender aos critérios de resistência à compressão simples, resistência à tração e ao módulo de resiliência para os lodos de ETE e de ETA. Todavia, a aplicação destes resíduos sem um adequado conhecimento, de possíveis impactos ambientais, torna esta prática questionável quanto à sua finalidade, pois pode apenas estar transferindo o problema.

Modelos reduzidos ou células de percolação que visem simular este 
fenômeno (possibilitando a coleta do material percolado para classificá-lo quanto à sua composição) são meios de complementar os ensaios mecânicos assegurando a sustentabilidade da técnica proposta. Alguns pesquisadores têm estudado meios de reproduzirem o contato da chuva com o pavimento e propuseram diversas maneiras de avaliar a caracterização ambiental (KNOP, 2003; FARIAS, 2005; ROJAS,2007; LUCENA, 2008; UBALDO et al., 2011).

Ubaldo et al., (2011) avaliaram o impacto ambiental da utilização do resíduo borra oleosa como base em obras de pavimentação. Os autores utilizaram um tanque teste de $4 \mathrm{~m}^{2}$ com a camada inferior de drenagem de brita, a intermediária formada por solo e a superior simulava uma base composta por brita, pó de pedra e borra oleosa. Neste tanque foram instalados dois canos perfurados e que possibilitaram a coleta do líquido durante dois meses.

Lucena (2008) abordou a utilização de misturas asfálticas contendo cascalhos de perfuração (resíduos oleosos - gerados nos processos de perfuração dos poços de extração de petróleo) em revestimentos asfálticos de estradas. Um modelo reduzido de um trecho experimental foi construído em uma caixa de madeira ( $1 \mathrm{~m} \mathrm{x} 1 \mathrm{~m} \mathrm{x}$ $0,3 \mathrm{~m}$ ) que apresentava uma camada de revestimento asfáltico sobre uma camada de areia. Na caixa foram realizados 12 orifícios onde foram inseridos canos de PVC para facilitar o procedimento de coleta do líquido resultante da aspersão da água.

Farias (2005) estudou a utilização de cinza pesada proveniente de processos siderúrgicos na pavimentação estabilizada com cal. $\mathrm{O}$ autor realizou um ensaio de percolação para avaliar a periculosidade do emprego da cinza pesada na pavimentação. Este consistiu na percolação da água da chuva em células de PVC contendo diversas misturas de solo com cinza pesada e solo com cinza estabilizado pela cal.

Knop (2003) e Rojas (2007) utilizaram ensaios de lixiviação em colunas para avaliar o potencial de encapsulamento em solos contaminados. Os autores consideraram este tipo de ensaio consistente pela possibilidade de simular as condições de campo, tais como a influência do grau de compactação do material e variações da condutividade hidráulica do solo encapsulado.

Autilização de modelos reduzidos com aplicação de resíduos, que apresentem matéria orgânica em sua composição, não deve avaliar apenas a concentração de metais, mas também parâmetros como umidade, recalque e pH para verificar se 
houve o encapsulamento e estabilização de resíduos de forma eficaz.

Portanto, este trabalho teve como objetivo estudar a capacidade de lixiviação dos metais pesados existentes lodo de ETA e de ETE no solo em modelos reduzidos, além da análise de parâmetros de umidade, $\mathrm{pH}$ e recalque.

\section{MATERIAIS E MÉTODOS}

\subsection{MATERIAIS}

As amostras do solo foram coletadas na jazida do Hélio, localizada no distrito de Mata Redonda no município do Alhandra - Paraíba, às margens da BR 101. O solo foi classificado como A-2-4 (areia siltosa), de acordo com o sistema de classificação TRB (Transportation Research Board) e como SW-SC (Areia bem graduada com argila) pelo SUCS (Sistema Unificado de Classificação dos Solos). A classificação TRB aponta como de bom a excelente um solo do tipo A-2-4 para uso em pavimentação.

O resíduo do lodo da ETA foi proveniente da "descarga" dos decantadores e filtros da ETA do Botafogo em Igarassu (750'28.6"S 3500'34.1”W), Estado de Pernambuco. A amostra do resíduo do lodo da ETE foi proveniente do leito de secagem da ETE do Cabanga em Recife-PE (84'50"S 3453'38”W) após passagem por tratamento primário. Foram utilizadas misturas de $10 \%$ de lodo de ETE $+8 \%$ de cimento + solo e $20 \%$ de lodo de ETA + 1\% de emulsão + solo, essas composições foram baseadas em pesquisas de Lucena et al (2014 -a) e Lucena et al (2014-b), que apresentaram os melhores resultados mecânicos nas pesquisas realizadas pelos autores. Para promover a estabilização da mistura foram utilizadas: cimento portland CPIIF-32 e emulsão asfáltica catiônica de ruptura lenta (RL-1C). Os estabilizantes foram adicionados ao solo, na proporção supracitada, e misturados manualmente até formar uma mistura homogênea.

\subsection{CONSTRUÇÃO DO MODELO}

Com a finalidade de monitorar o impacto ambiental, causado pela utilização 
de resíduos do lodo em base e sub-base de pavimentos, foi construído um modelo reduzido, das misturas de solo + lodo + estabilizante, para o lodo de ETE e para o lodo de ETA. O modelo serviu para avaliar a possível contaminação da água e do solo quando ocorrer a percolação da água da chuva.

O modelo tinha volume de aproximadamente de $0,5 \mathrm{~m}^{3}$ e constou de quatro camadas para se aproximar de configuração próxima a de campo. A camada inferior foi constituída de uma camada de brita para impedir que o ralo situado no fundo do tanque viesse a entupir o dreno. A camada seguinte foi constituída do solo puro, e apresentava um dreno situado no meio da camada para coleta de líquidos. Em seguida foi situada uma camada da mistura de solo + resíduo + estabilizante, onde foi colocado outro tubo de PVC na parte inferior desta e por último foi colocada uma fina camada de revestimento asfáltico, apenas na parte central, para permitir a infiltração da água da chuva pelas laterais.

Os modelos reduzidos foram submetidos às condições atmosféricas. Cada tanque experimental foi dotado de tubos de drenagem e medidores de recalques superficiais e de profundidade. Foram observados e analisados, concomitantemente ao estudo de lixiviação de metais, parâmetros como recalque, variação de $\mathrm{pH}$ e umidade. Estes são importantes para analisar se a mistura se encontra estabilizada ou permanece sofrendo decomposições e reações químicas.

Para a confecção do modelo reduzido foi utilizada uma caixa de fibra de vidro de capacidade de $0,5 \mathrm{~m}^{3}$, dividida ao meio, onde em um lado foi analisado o comportamento da mistura com lodo de ETE (solo $+10 \%$ de lodo de ETE $+8 \%$ de cimento) e no outro a mistura com ETA (solo $+20 \%$ de lodo de ETA $+1 \%$ de emulsão).

O modelo foi composto das seguintes camadas (Figura 01):

- $10 \mathrm{~cm}$ de espessura de brita $19 \mathrm{~mm}$, constituindo uma camada drenante;

- $9 \mathrm{~cm}$ de espessura do solo granular A-2-4 (solo puro);

- $11 \mathrm{~cm}$ de espessura de um solo argiloso A-7 (solo puro);

- $20 \mathrm{~cm}$ de espessura da mistura do solo com o resíduo e o estabilizante;

- $5 \mathrm{~cm}$ de espessura e $50 \mathrm{~cm}$ de largura de uma camada de revestimento asfáltico para possibilitar a infiltração de água pelas laterais. 


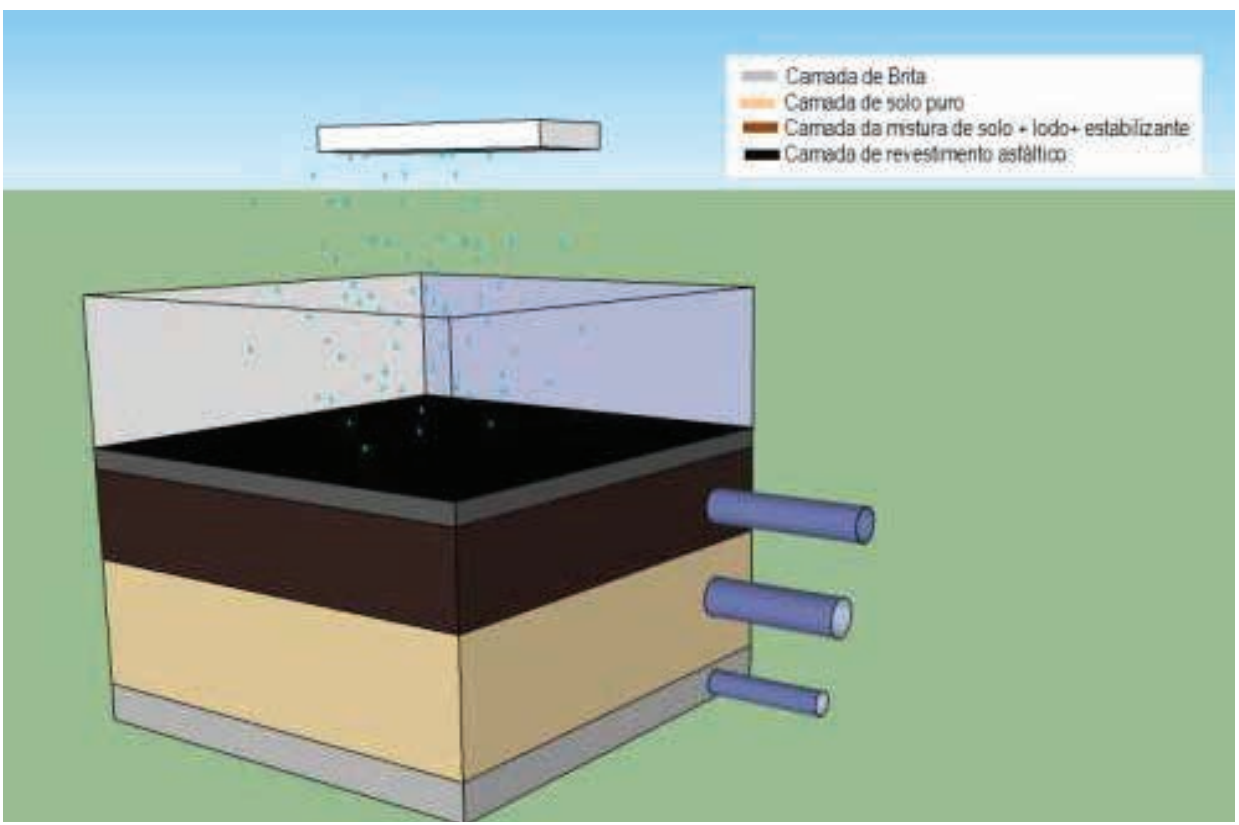

Figura 1. Esquema da configuração do modelo reduzido construído para este experimento

Foram realizados furos no centro de cada camada e instalado tubos de PVC para possibilitar a coleta de material. As misturas foram feitas na umidade ótima com o auxílio de um misturador mecânico e compactadas com o soquete utilizado no ensaio de compactação de solos.

O modelo teve os parâmetros avaliados bimestralmente durante um ano. O acompanhamento da evolução dos recalques foi realizado a partir da instalação de placas metálicas e de discos magnéticos. Os recalques foram estimados em função do deslocamento vertical das placas e discos situados na superfície e outro em profundidade. Para acompanhamento do $\mathrm{pH}$ e da variação de umidade foram coletadas amostras e ensaiadas em laboratório, com o auxílio de um phmêtro e utilizando o método da estufa, respectivamente.

Após este período, o modelo foi aberto e foram realizados ensaios de granulometria, índices de consistência por meio dos Limites de Atterberg (Limite de Liquidez (LL), Limite de Plasticidade (LP)), massa específica e ensaios de absorção atômica no extrato solubilizado de ambas as camadas de solo. 


\section{RESULTADO E DISCUSSÃO}

\subsection{MONITORAMENTO DO MODELO}

O modelo reduzido foi construído e monitorado no Laboratório de Solos da Universidade Federal de Campina Grande (UFCG). As análises de umidade, pH, recalque e lixiviação de metais foram realizadas de dois em dois meses. O modelo foi concebido com seção transversal circular a fim de facilitar a distribuição e compactação do solo em seu interior, uniformizar a distribuição das pressões laterais na parede interna e evitar caminhos preferenciais de percolação da água.

As dimensões das camadas constituintes foram definidas com o objetivo de se atingir uma espessura representativa para coleta e análise do solo. $\mathrm{O}$ tempo de observação do modelo reduzido foi de um ano com coleta e avaliação bimestral. A Tabela 1 apresenta os resultados alcançados para as análises realizadas para os parâmetros pH, umidade e recalque e a data de coleta das amostras para análises.

Tabela 1. Parâmetros do modelo reduzido

(continua)

\begin{tabular}{ccccc}
\hline Data & Mistura & $\mathrm{pH}$ & Umidade (\%) & Recalque (mm) \\
\hline \multirow{2}{*}{$06 / 2012$} & Solo+lodo ETA+ emulsão & 7,0 & 18,0 & 11 \\
& Solo+lodo ETE + cimento & 12,2 & 15,5 & 21 \\
\hline \multirow{2}{*}{$08 / 2012$} & Solo+lodo ETA+ emulsão & 7,0 & 7,31 & 11 \\
& Solo+lodo ETE+ cimento & 10,0 & 10,89 & 21 \\
\hline \multirow{2}{*}{$10 / 2012$} & Solo+lodo ETA+ emulsão & 7,0 & 9,0 & 11 \\
& Solo+lodo ETE+ cimento & 8,0 & 9,2 & 21 \\
\hline \multirow{2}{*}{$12 / 2012$} & Solo+lodo ETA+ emulsão & 7,0 & 9,4 & 11 \\
& Solo+lodo ETE+ cimento & 8,0 & 9,2 & 21 \\
\hline \multirow{2}{*}{$02 / 2013$} & Solo+lodo ETA+ emulsão & 7,0 & 8,3 & 11 \\
& Solo+lodo ETE + cimento & 8,0 & 9,0 & 21 \\
\hline
\end{tabular}


(conclusão)

\begin{tabular}{ccccc}
\hline Data & Mistura & $\mathrm{pH}$ & Umidade (\%) & Recalque (mm) \\
\hline \multirow{2}{*}{$04 / 2013$} & Solo+lodo ETA+ emulsão & 7,0 & 9,0 & 11 \\
& Solo+lodo ETE+ cimento & 8,0 & 9,5 & 21 \\
\hline \multirow{2}{*}{$06 / 2013$} & Solo+lodo ETA+ emulsão & 7,0 & 9,0 & 11 \\
& Solo+lodo ETE+ cimento & 8,0 & 9,7 & 21 \\
\hline \multirow{2}{*}{$07 / 2013$} & Solo+lodo ETA+ emulsão & 7,0 & 9,3 & 11 \\
& Solo+lodo ETE+ cimento & 8,0 & 10,2 & 21 \\
\hline
\end{tabular}

Segundo Costa (2004), o pH dos solos varia tipicamente entre 4,0 e 8,5, podendo ocorrer em solos com pH maior que 10,0 em áreas semiáridas e áridas e menor que 3,0 em solos com horizontes sulfúricos.

Analisando-se os resultados das misturas estabilizadas de lodo de ETE e de ETA, usados no modelo reduzido, verifica-se que apresentam $\mathrm{pH}$, nos primeiros meses, de 12 e 7 , respectivamente. Ou seja, a mistura com lodo de ETA teria um $\mathrm{pH}$ neutro enquanto a com lodo de ETE apresenta $\mathrm{pH}$ alcalino, possivelmente em virtude da adição do estabilizante cimento, e estão uma unidade acima do obtido para as amostras de solo puro ( $\mathrm{pH} \mathrm{6,0)} \mathrm{e} \mathrm{solo} \mathrm{com} \mathrm{lodo} \mathrm{de} \mathrm{ETE} \mathrm{(} \mathrm{pH} \mathrm{6,3)} \mathrm{e} \mathrm{ETA} \mathrm{(pH}$ 6,2) sem estabilizante.

Costa (2004) afirma que o pH num solo não constitui um valor constante e característico e sofre oscilações que podem ser da ordem de grandeza de uma unidade, dependendo de fatores como teor de água no solo, natureza e proporções de sais. Portanto, este aumento de pH deve-se à adição de estabilizantes à mistura.

Ainda de acordo com Costa (2004), a alcalinidade verificada, em geral, ocorre quando não há arrastamento das bases por água de infiltração e existe um elevado grau de saturação do complexo de troca. A presença de sais solúveis, nomeadamente quando se trata de sais provenientes de bases fortes, como no caso da adição do cimento à mistura, podem contribuir para o aumento da concentração de hidroxila.

Verifica-se que após dois meses de funcionamento do modelo reduzido, o aumento do $\mathrm{pH}$ das misturas com lodo de ETE favorece a formação de produtos cimentantes. Para idades superiores, a tendência é o decréscimo do pH em razão do término das reações de hidratação do cimento, fato que foi comprovado para os demais meses. 
A importância da verificação deste parâmetro deve-se ao cuidado com a drenagem do pavimento, pois a percolação da água provoca aumento da acidez do solo, mudando as características químicas sobre as quais este se encontra estabilizado. À medida que o pH muda de alcalino para ácido, ocorrem novamente modificações estruturais, gerando a tendência de voltar à condição de material não estabilizado e a consequente perda de resistência com a incorporação de estabilizantes (LUCENA et al., 2014-a).

A análise do parâmetro de recalque, em virtude da presença de matéria orgânica presente nos resíduos, evidencia que estas se encontram, possivelmente, estabilizadas, uma vez que não houve alteração significativa nem no recalque e nem umidade mesmo em condições severas de precipitação (correspondente às chuvas de inverno da região).

Lucena et al. (2014-a) e Lucena et al.(2014-b) caracterizaram os resíduos de acordo com a NBR 10005/2004 e NBR 10006/2004, ambos foram classificados como não tóxico e de "Classe II A" (Não Inerte). O lodo de ETE apresentou no extrato solubilizado uma concentração superior ao lodo de ETA para os metais Pb, Fe e Ni, porém, o lodo de ETA possui uma concentração de Mn bem mais elevada que o lodo de ETE. Além disso, os valores obtidos para o Níquel (resíduo de ETE) e Alumínio (resíduo de ETA) encontram-se acima do preconizado pelo Ministério da Saúde (MS) e pela Companhia de Tecnologia de Saneamento Ambiental (Cetesb). Portanto, o lodo de ETA é classificado como resíduo perigoso por estas instituições.

Com a coleta do líquido que escoou pelos orifícios instalados no modelo foram realizados ensaios de espectroscopia por absorção atômica. A Tabela 2 apresenta as concentrações obtidas para os parâmetros analisados. Os dados da Tabela indicam que não houve lixiviação de metais pesados nos períodos analisados para ambos os resíduos, podendo-se inferir que a aplicação da técnica de encapsulamento foi satisfatória. Os padrões preconizados pela Cetesb e pelo Ministério da Saúde são relativos à utilização da água para consumo humano. 
Tabela 2. Constituintes químicos encontrados no líquido coletado no modelo reduzido

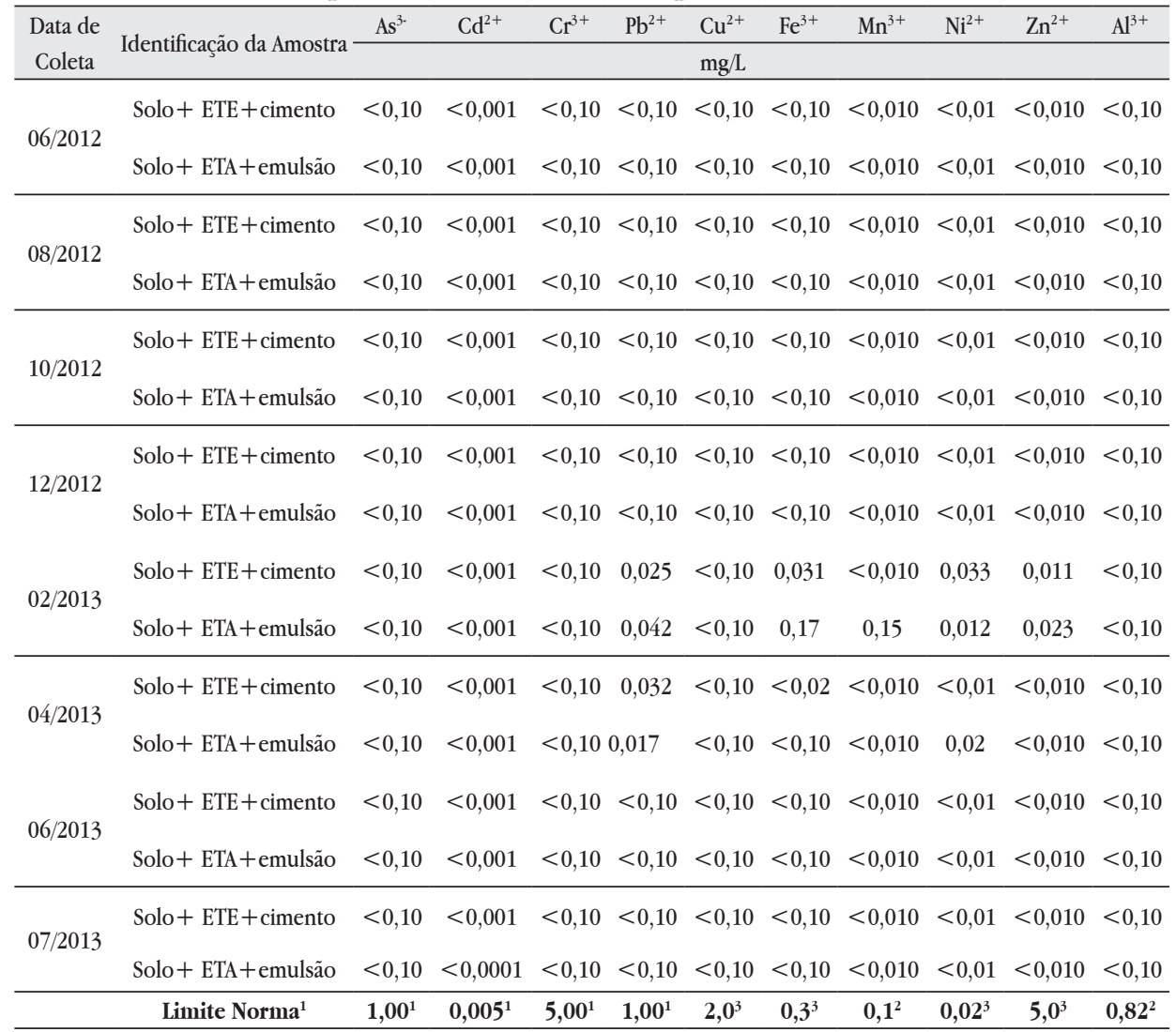

Nota: 1 Parâmetros e limites máximos no extrato lixiviado conforme recomendação da ABNT NBR 10005 (2004b) e ABNT NBR 10006 (2004c) e CFR (2003). 2 Valores baseados no Ministério da Saúde (MS) - Portaria № 518 de 2004 (MS, 2004). 3 Valores sugeridos pela Companhia de Tecnologia de Saneamento Ambiental (Cetesb) - portaria n 195 de 2005 (CETESB,2005)

Destaca-se que o estudo realizado nesta pesquisa ocorreu estritamente para camadas de base e sub-base de pavimento com revestimento asfáltico. Caso deseje aplicá-la com outros tipos de revestimento são necessárias análises suplementares de condutividade hidráulica e ensaios de coluna. Além disto, é importante a análise, a curto e longo prazo, de parâmetros biológicos e químicos. A análise feita neste item deve ser estendida para a migração dos solúveis em meios saturados e não saturados. 


\subsection{CARACTERIZAÇÃO FÍSICO-QUÍMICA DAS CAMADAS DO MODELO REDUZIDO}

Após o período de monitoramento (1 ano) o modelo foi aberto e foram retiradas amostras dos solos para análise na camada estabilizada ( $1^{\mathrm{a}}$ camada) e na camada constituída de solo granular ( $2^{\mathrm{a}}$ camada). Na Tabela 3 estão contidos os resultados de análise de metais realizados nos extratos solubilizados produzidos a partir das amostras das camadas supracitadas.

Tabela 3. Constituintes químicos encontrados nas camadas de solo SOLUBILIZADO no modelo reduzido contendo lodo de ETE e ETA

\begin{tabular}{|c|c|c|c|c|c|c|c|c|c|c|c|}
\hline \multirow{2}{*}{ Resíduo } & \multirow{2}{*}{$\begin{array}{c}\text { Identificação da } \\
\text { amostra }\end{array}$} & $\mathrm{As}^{3-}$ & $\mathrm{Cd}^{2+}$ & $\mathrm{Cr}^{3+}$ & $\mathrm{Pb}^{2+}$ & $\mathrm{Cu}^{2+}$ & $\mathrm{Fe}^{3+}$ & $\mathrm{Mn}^{3+}$ & $\mathrm{Ni}^{2+}$ & $\mathrm{Zn}^{2+}$ & $\mathrm{Al}^{3+}$ \\
\hline & & \multicolumn{10}{|c|}{$\mathrm{mg} / \mathrm{L}$} \\
\hline \multirow{2}{*}{$\begin{array}{l}\text { Lodo de } \\
\text { ETA }\end{array}$} & $1^{\mathrm{a}}$ camada & $<0,10$ & $<0,001$ & 0,06 & 0,18 & $<0,10$ & 114 & 0,065 & 0,086 & 0,069 & 240 \\
\hline & $2^{\mathrm{a}}$ camada & $<0,10$ & $<0,001$ & 0,08 & 0,18 & $<0,10$ & 102 & 0,057 & 0,090 & 0,13 & 245 \\
\hline \multirow{3}{*}{$\begin{array}{l}\text { Lodo de } \\
\text { ETE }\end{array}$} & $1^{\mathrm{a}}$ camada & $<0,10$ & $<0,001$ & $<0,005$ & 0,012 & $<0,10$ & 0,03 & $<0,010$ & 0,22 & 0,011 & $<0,10$ \\
\hline & $2^{\mathrm{a}}$ camada & $<0,10$ & $<0,001$ & $<0,05$ & 0,081 & $<0,10$ & 64,4 & 0,040 & 0,043 & 0,038 & $<0,10$ \\
\hline & Limite norma $^{1}$ & $0,01^{1}$ & $0,005^{1}$ & $0,05^{1}$ & $0,01^{1}$ & $2,0^{3}$ & $0,3^{3}$ & $0,1^{2}$ & $0,02^{3}$ & $5,0^{3}$ & $0,2^{2}$ \\
\hline
\end{tabular}

Para as amostras com lodo de ETA verifica-se concentrações similares de metais em ambas as camadas, apresentando concentrações de $\mathrm{Cr}$ e $\mathrm{Pb}$ acima do permitido pela NBR 1004/2004, de Ni e Fe acima do recomendado pelo Ministério da Saúde e de Al pela Cetesb. As altas concentrações de Fe e Al são justificadas pela adição do coagulante durante a etapa de tratamento dos efluentes, observa-se que houve carreamento destes metais da primeira para a segunda camada, uma vez que estes não fazem parte da composição do solo puro.

Nas amostras com lodo de ETE, observa-se que as concentrações de Fe e Pb são superiores na camada de solo granular do que na amostra estabilizada, indicando provável carreamento de íons.

Portanto, embora não tenha sido observada a lixiviação dos metais nos líquidos coletados durante o período de análise, verificaram-se concentrações de metais acima do preconizado pela NBR 1005/2004 em ambas as camadas de solo puro, o que faz com que estas camadas sejam classificadas como não inerte.

Apesar dos teores acima do permitido para Cetesb e Ministério da Saúde, estes são padrões relativos ao consumo da água, portanto existe uma tolerância 
maior, uma vez que este estudo está ocorrendo em camadas de solo. Entretanto, deve-se ter cuidado, pois a presença destes no solo permanece como fonte de contaminação e pode vir a sofrer processo de transporte e atingir o lençol freático dependendo da posição deste.

As Figuras 2 e 3 apresentam a distribuição dos tamanhos de grãos para as camadas de solo estabilizadas no modelo reduzido. Verifica-se que para ambas as figuras a granulometria da camada estabilizada assemelha-se a da camada de solo puro. Este fato indica que após algum tempo ocorre a formação de massas monolíticas, com dimensões superiores às partículas de lodo, evidenciando o encapsulamento físico da amostra. Observou-se redução da plasticidade e da massa específica dos grãos do solo com a incorporação dos resíduos e isso corrobora a ocorrência das reações químicas uma vez que os resíduos não apresentam plasticidade e têm menor massa específica (cerca de 20\%).

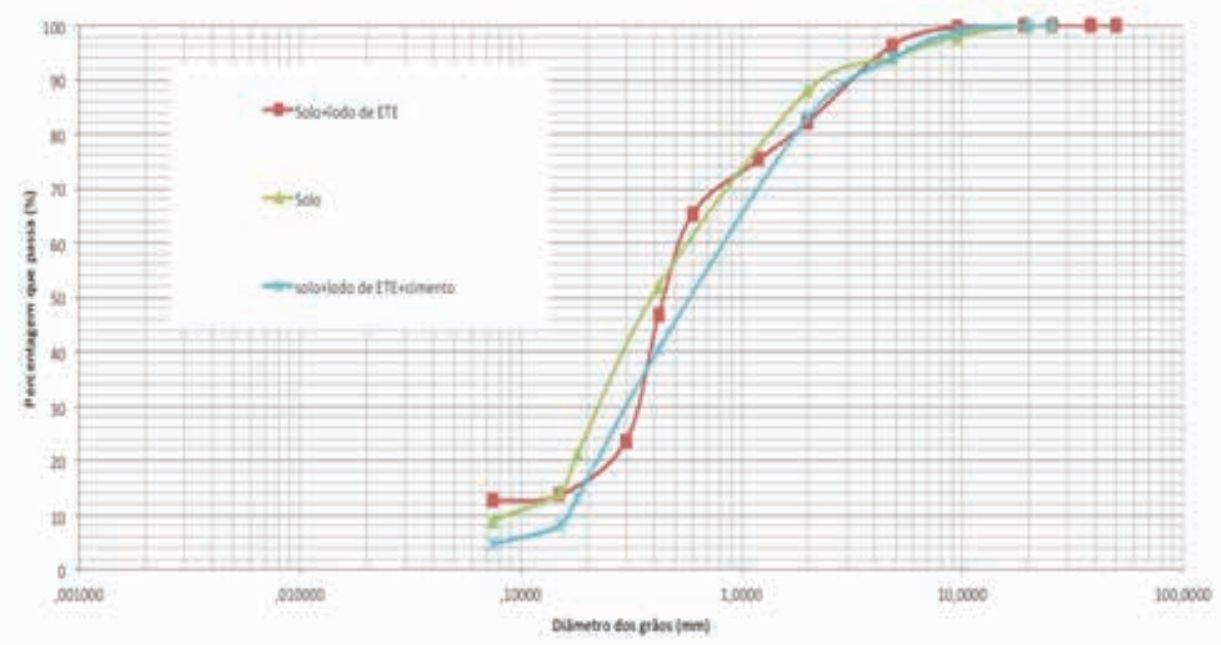

Figura 2. Curva de distribuição dos tamanhos de partículas com lodo de ETE 


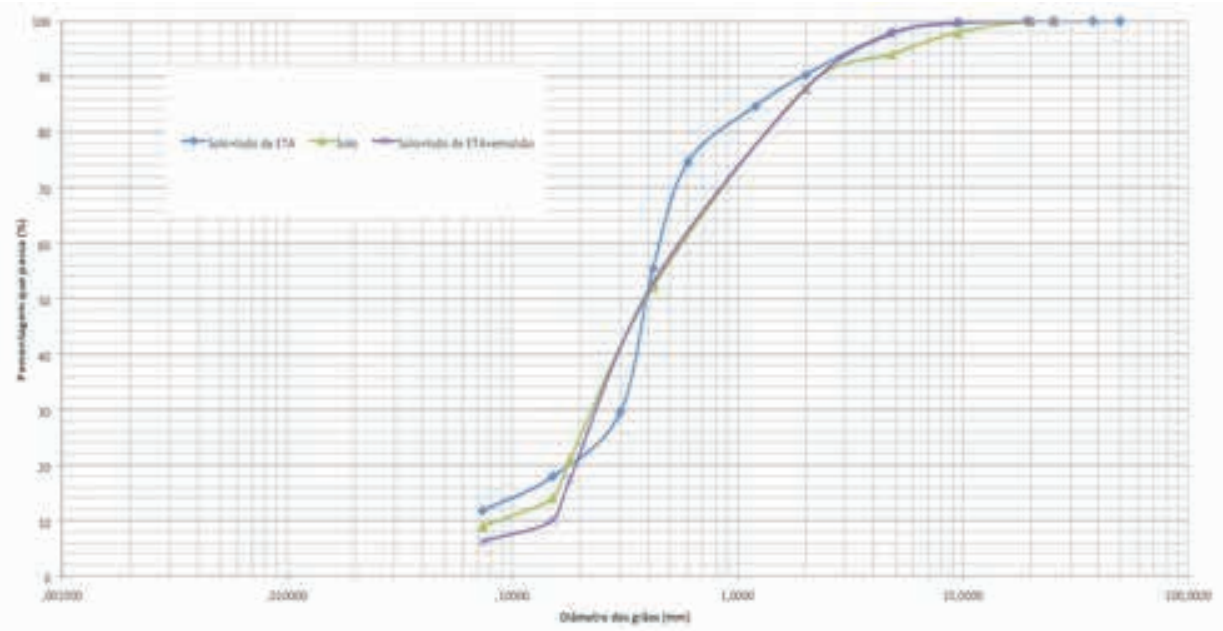

Figura 3. Curva de distribuição dos tamanhos de partículas com lodo de ETA

\section{CONSIDERAÇÕES FINAIS}

Os ensaios de extrato lixiviado realizados para as misturas de solo com lodo de ETA e emulsão e solo com lodo de ETE e cimento apresentaram valores inferiores ao preconizado pelas normas vigentes. Este fato indica que caso a água percolada atinja o lençol freático, esta não trará riscos à saúde pública. Os parâmetros de ph, umidade e recalque, observados no modelo reduzido, não tiveram modificações significativas durante o período de observação. Este fato indica que uma base estabilizada, nas condições analisadas não apresentaria alterações mecânicas em curto/médio prazo em razão de reações químicas e/ou biológicas com o resíduo.

A análise dos extratos solubilizados evidencia a presença de metais pesados na sua constituição ( $\mathrm{Pb}$ e Ni), embora esta concentração seja inferior a verificada nos resíduos puros. As análises físicas das camadas de solo indicaram aumento nas dimensões dos tamanhos de grãos após o processo de estabilização, este fato decorre da formação de uma massa monolítica com o encapsulamento dos resíduos.

Os resultados do monitoramento indicaram que a utilização dos resíduos não apresenta consequências ambientais relevantes em curto/médio prazo. Embora não seja avaliado nesta pesquisa, deve-se destacar que a análise do fluxo 
de não saturados é relevante, bem como o transporte de contaminantes, para o entendimento do comportamento de estabilização dos resíduos, principalmente quando se tem a presença de compostos solúveis.

Conclui-se que a disposição final dos resíduos em camadas de solo pode vir a sanar um grave problema social e ambiental que é o descarte incorreto dos resíduos de ETA e ETE. Estes, que antes promoviam impactos na saúde da população, são encapsulados promovendo ganhos econômicos (diminuição dos gastos com saúde pública) e sociais (diminuição do odor proveniente da disposição dos resíduos).

\section{REFERÊNCIAS}

ACHON, C. L.; BARROSO, M. M.; CORDEIRO, J. S. Leito de drenagem: sistema natura para redução de volume de lodo de estação de tratamento de água. Revista Engenharia Sanitária e Ambiental, São Paulo, v. 13, n. 1, p. 54-62, 2008.

AYDILEK, A.; EDIL, T. Solidification/Stabilization of PCB-Contaminated Wastewater Treatment Sludges. In: GEOCONGRESS. Nova Orleans, 2008. p. 724-73.

BRAR, S. K.;VERMA, M.; TYAGI, R. D.; SURAMPALLI, R. Y. Value addition of wastewater sludge: future course in sludge reutilization. Pract. Period. Hazard. Toxic Radioact. Waste Manage, Quebec, v. 13, n. 1, 59-74, 2009.

CHANG, F.C.; LIN, J.D.; TSAI, C.C.; WANG, K.S. Study on cement mortar and concrete made with sewage sludge ash. Water Sci. Technol., v. 62, p. 1689-1693, 2010.

COSTA, J.B.; Caracterização e constituição de um solo. 7. ed. Lisboa: Fundação Calouste Gulbenkian, 2004.

D'ANDREA, A.; FUSTAINO, C.; TOZZO, C. Recycling Dredged Sludge in Asphalt Pavement. J. Mater. Civ. Eng., Roma, v. 26, n. 10, out. 2014.

DYER, T., HALLIDAY, J., AND DHIR, R. Hydration Chemistry of Sewage Sludge Ash Used as a Cement Component. J. Mater. Civ. Eng., v. 23, n. 5, p. 648-655, 2011. 
FARIAS, E.R.; A Utilização de misturas solo/cinza pesada na pavimentação: análise de aspectos de comportamento mecânico e ambiental. 2005. Dissertação (Mestrado em Engenharia Civil) - Universidade Federal de Santa Catarina, Florianópolis, 2005.

GUERRA, R.C.; ANGELIS, D.F.D. Classificação e biodegradação de lodo de estações de tratamento de água para descarte em aterro sanitário. Arq. Inst. Biol., São Paulo, v. 72, n. 1, p.87-91, jan./mar., 2005.

GUERRERO, R.; BEVILAQUA, D. Biotrickling filtration of biogas produced from the wastewater treatment plant of a brewery. J. Environ. Eng., Araraquara, v. 141, n. 8, 2015.

HAMOOD, A.; KHATIB, J. The use of Raw Sewage Sludge (RSS) as a water replacement in cement-based mixes. Fort Worth: ICSDEC 2012. p. 1001-1008.

JANG, J.; AHN, J. High-Temperature Microwave $\mathrm{NaOH}$ Pretreatment of WasteActivated Sludge for Anaerobic Digestion. J. Environ. Eng., Chuncheon, v. 141, n. 8, 2015.

KE, X.; ZHANG, G.; WAN, T.; GAO, F. Heavy-Metal Accumulation in Low-Sludge Wastewater Treatment Technique: Sonication-Cryptic Growth. J. Environ. Eng., Pequim, v. 138, n. Especial: Advances in Research and Development of Sustainable Environmental Technologies, p. 248-251, 2012.

KNOP, A. Encapsulamento de solos contaminados por hidrocarbonetos. 2003. Dissertação (Mestrado em Engenharia Civil) - Universidade Federal do Rio Grande do Sul, Porto Alegre, 2003.

LI, Y.; WANG, H.; ZHANG, J.; WANG, J.; LAN, O. Co-Processing Sewage Sludge in Cement Kiln in China. Journal of Water Resource and Protection, Wuhan, v. 5, n. 9, p. 906-910, 2013

LIN, C.; ZHU, W.; HAN, J. Strength and Leachability of Solidified Sewage Sludge with Different Additives. J. Mater. Civ. Eng., v. 25, n. 11, p. 1594-1601, 2013. 
LIN, Y.; ZHOU, S.; LI, F.; LIN, Y. Utilization of municipal sewage sludge as additives for the production of eco-cement. Journal of Hazardous Materials, Guangzhou, v. 213-214, p. 457-465, 2012.

LIU, S.; NING, P.; ZHU, N.; LI, L.; GONG, X. Semicontinuous operation of one-stage autothermal thermophilic aerobic digestion of sewage sludge: effects of retention time. J. Environ. Eng., v. 139, n. 3, p. 422-427, 2013.

LUCENA, A.E.F.L, Utilização de cascalhos de perfuração oriundos das atividades de exploração de petróleo em revestimentos asfálticos de estradas. 2008. Tese (Doutorado em Engenharia de Processos) - Universidade Federal de Campina Grande, Campina Grande, 2008.

LUCENA, L.C.; JUCA, J.F.; SOARES, J.B.; MARINHO FILHO, P.G. Use of wastewater sludge for base and subbase of road pavements, Transportation research part D, Campina Grande, v. 33, p. 210-219, 2014a

LUCENA, L.C.; JUCA, J.F.; SOARES, J.B.; PORTELA, M.G. Potential uses of sewage sludge in highway construction. Journal of Materials in Civil Engineering, Campina Grande, v. 26, n. 9, 2014b

MARTÍN-PASCUAL, J.; REBOLEIRO-RIVAS, P.; LÓPEZ-LÓPEZ, C.; LEYVA-DÍAZ, J.; JOVER, M.; MUÑIO, M.; GONZÁLEZ-LÓPEZ, J.; POYATOS, J. Effect of the Filling Ratio, MLSS, Hydraulic Retention Time, and Temperature on the Behavior of the Hybrid Biomass in a Hybrid Moving Bed Membrane Bioreactor Plant to Treat Urban Wastewater. J. Environ. Eng., Granada, v. 141, n. 7, 2015

PEREIRA, S.L.M. Características físicas, químicas e microbiológicas do lodo das lagoas da ETA Gramame. 2011. Dissertação (Mestrado em Engenharia Civil e Ambiental) - Universidade Federal da Paraíba, João Pessoa, 2011.

PROUST, D.; MATHÉ, V.; LÉVÊQUE, F. Distribution and Mobility of Zn, $\mathrm{Pb}$ and Cd in a Sewage Sludge-Amended Soil. Open Journal of Soil Science, v. 3, n. 8, p. 347$355,2013$. 
ROJAS, J.W.J. Estudo da remediação de solo contaminado por borra oleosa ácida utilizando a técnica de encapsulamento. 2007. Dissertação (Mestrado em Engenharia Civil). Universidade Federal do Rio Grande do Sul. Porto Alegre, 2007.

SMOL, M.; KULCZYCKA, J.; HENCLIK, A.; GORAZDA, K.; WZOREK, Z. The possible use of sewage sludge ash (SSA) in the construction industry as a way towards a circular economy. Journal of Cleaner Production, Crackovia, v. 95, p. 45-54, 2015.

TEIXEIRA, S. R.; SOUZA, S. A.; SOUZA, N. R.; ALÉSSIO, P.; SANTOS, G. T. A.. Efeito da adição de lodo de estação de tratamento de água (ETA) nas propriedades de material cerâmico estrutural. Cerâmica, São Paulo, v.52, n.323, july./sept. 2006.

TENZA-ABRIL, A.; SAVAL, J.; CUENCA, A. Using Sewage-Sludge Ash as Filler in Bituminous Mixes. J. Mater. Civ. Eng., Alicante, v. 27, n. 4, 2015.

UBALDO, M.O.; FRITZEN, M.A.; MOTTA, L.M.G.; NASCIMENTO, L.A..H; Utilização do resíduo borra oleosa em pavimentação. In: CILA CONGRESSO IBEROLATINOAMERICANO DE ASFALTO, 16., 2011, Rio de Janeiro. Anais... Rio de Janeiro, 2011.

Recebido em: 01 de junbo de 2015 Aceito em: 06 de agosto de 2016 